\title{
Smoking inequality across genders and socio-economic positions. Evidence from Italian data
}

\author{
Cinzia Di Novi ${ }^{1,2,3} \cdot$ Rowena Jacobs ${ }^{4} \cdot{\text { Matteo } \text { Migheli }^{5} \text { (D }}$
}

Published online: 2 September 2020

(c) The Author(s) 2020

\begin{abstract}
There has been a dearth of literature on smoking inequalities, in spite of its contribution to health inequalities. We exploit Italian individual-level data from repeated cross-sections of the annual household survey, "Aspects of Daily Life," that was part of the Multipurpose Survey carried out by the Italian National Statistical Office (ISTAT) for the period 1999-2012 to identify the main socio-demographic characteristics that determine smoking inequalities. We use the Concentration Index to identify in which groups smoking is relatively more prevalent. We find that, among men, prorich inequality is driven by members of the lower socio-economic positions, while we observe the opposite for women. We encourage policymakers to address the issue of smoking inequalities, which the current policies have largely disregarded.
\end{abstract}

Keywords Smoking inequality $\cdot$ Italy $\cdot$ Gender $\cdot$ Socio-economic positions

JEL Codes I14 $\cdot$ I18 $\cdot$ J16

\section{Introduction}

There exists a substantial literature showing that a healthier lifestyle is one of the key driving factors for good health (Contoyannis and Jones 2004; Balia and Jones 2008; Di Novi 2010, 2013). However, the literature also shows that healthier lifestyles is generally distributed disproportionately according to socioeconomic position indica-

$凶 \quad$ Matteo Migheli

matteo.migheli@unito.it

1 Department of Economics and Management, University of Pavia, Pavia, Italy

2 Health, Econometrics and Data Group, University of York, York, UK

3 LCSR, National Research University Higher School of Economics, Moscow, Russian Federation

4 Centre for Health Economics, University of York, York, UK

5 Department of Economics and Statistics, University of Torino, Lungo Dora Siena, 100 Torino, Italy 
tors such as education, occupation, and income, which shape individuals' behaviours leading to inequalities in health outcomes i.e. health disparities between people of different socio-economic conditions (Mackenbach 2006; Baker 2014; Bambra et al. 2016). As international institutions and governments enact laws and implement policies to decrease socioeconomic inequalities, so they do with health inequalities (HIs), on the one side, because the latter are related to the former and vice-versa, on the other, as health inequality hinders human development. Indeed, Woodward and Kawachi (2000) highlight that such an inequality is unfair and avoidable through public programs; in addition, as it engenders negative externalities, its reduction benefits the entire population. However, health depends also on individuals' behaviours: drinking alcohol, smoking, neglecting physical exercise are examples of behaviours that hinder one's health. Studying these behaviours and their causes may therefore help to design and implement effective policies to reduce HIs; in particular, the three mentioned before are among the most widespread and studied by health literature. The present paper focuses in particular on smoking and some of the socio-economic determinants that help explaining its unequal distribution of smoking prevalence in the population.

In many European countries, smoking is still a major cause of premature morbidity and mortality and one of the largest contributors to mortality and morbidity difference between those with low and high socioeconomic position, although differences between Northern and Mediterranean countries exist. Cavelaars et al. (2000), for example, show that smoking prevalence is higher among low-educated than highly educated women in Northern Europe, while the opposite happens in Mediterranean countries. The magnitude and the persistence of the problem necessitate the development of comprehensive actions aimed at reducing tobacco consumption especially among lower socio-economic positions (Kunst et al. 2004). Several governments have enacted measures - spanning from increasing taxes on tobacco to banning smoking in several places and situations. The effects of these legislative approaches vary: on the one hand, increased taxes raise the final price of the products, which may foster smuggling, thus reducing the effectiveness of the measure, although the effect of smuggling is not very large (Yurekli and Zhang 2000). On the other hand, increased taxes have the twofold effect of discouraging smoking and reinforcing the message that the consumption of tobacco represents a health risk. Banning smoking in public places is another strategy used by legislators to reduce smoking rates. However, these interventions aim to reduce overall prevalence of tobacco consumption rather than inequalities in smoking. Otherwise, while taxation decreases smoking inequality, some other policies aimed to reduce smoking prevalence, such as smoking cessation programs, may have the opposite effect, i.e. that of increasing smoking inequality (Brown et al. 2014).

A growing literature (Lopez et al. 1994; Pampel 2005; Mackenbach 2006; Veday 2014) suggests a typical trajectory for smoking uptake that fits the pattern proposed by the theory of diffusion of innovations (Rogers 2003). According to this literature, the rise and fall of smoking is analogous to an epidemic, where smoking spreads from relatively small parts of a population to other parts and then declines. The trajectory follows four stages: In the first stage, smoking was undertaken mainly by men in higher socio-economic groups (early adopters), who were more open to innovations and endowed with sufficient resources to adopt them. In the second stage, smoking 
became more common and more equally distributed across a large part of the population (early majority); the socioeconomic gradient diminished because of increased prevalence among less affluent socioeconomic groups. In the third stage, the prevalence of smoking has peaked and started to decline, especially among those who are better off, while remaining relatively constant among the rest of the population (later majority). In the last stage, smoking will become a habit of lower socioeconomic groups (laggards) who adopted it later in the diffusion process. In the smoking epidemic, women lag men by one or two decades. The later spread among women may be one of the reasons for the continuing gender heterogeneity in smoking prevalence. According to this four-stage trajectory, another source of heterogeneity in smoking prevalence is the individuals' socioeconomic position which plays a pivotal role in the diffusion of the smoking habit, as those in higher socioeconomics status are the first to adopt smoking early in the epidemic and the first to reject it later (Di Novi and Marenzi 2019). Of course, as there is no pathological agent that transmits a behaviour such as smoking is, the epidemic contagion is related to individuals gender and socioeconomic position but also relies on sociological phenomena such as mimesis and the will of following the "rules of the game" of the society and, in particular, of the reference group of peers (Dixon and Banwell 2009). The scope of this paper is not to enter the debate about what smoking is from a theoretical viewpoint; however the mentioned framework may be useful to interpret the empirical results.

In this paper, we analyse trends in inequalities in smoking by employing individuallevel Italian data drawn from the 1999-2012 cross-sectional survey "Indagine Multiscopo sulle Famiglie, Aspetti della Vita Quotidiana”, which is part of the Istat Multiscopo survey carried out each year by the Italian National Statistical Office (ISTAT). We measure socio-economic inequalities in tobacco smoking by means of the Wagstaff and van Doorslaer (2000) concentration index, with the adjustment proposed by Erreygers (2009). We decompose Erreygers index into the contributions of socio-economic status and demographic factors (Van Doorslaer Koolman and Jones 2004) which helps identify the drivers of the inequality. In addition to this, we split the sample by gender and conduct the analysis on these sub-samples. We also consider the relationship between the economic cycle and smoking inequality and whether during periods of financial strain, individuals of different socio-economic status have different uptake rates into smoking.

Italy presents one of the lowest rate of health inequality in Europe but smoking inequality is unexpectedly high (Mackenbach 2006). Therefore, Italy represents an interesting case study, as the phenomenon of inequality in smoking prevalence seems at odds with other indicators of health inequality. While several country studies on smoking prevalence and its socio-economic determinants already exist (the next section provides a review of the most important), behaviours and their socio-economic causes may differ from a country to another. Consequently, adding evidence helps isolating the common causes and highlighting those that are country specific. Such a goal is relevant per se as it may be useful to guide anti-smoking policies at international and national level. The main novelty of the paper, instead, is that, in the case of Italy, this is the first work to present an in-depth analysis of socio-economic determinants of smoking inequality in Italy, so providing new insights on the topic. 
In January 2003, Italy became the first large European Union country to approve a strict and comprehensive smoking ban, which came into effect in January 2005. The Italian government banned smoking in all indoor public places, including offices, cafes, restaurants (except for a few with separate and regulated smoking areas), airports, and railway stations. In order to deter young people from taking up the smoking habit, in January 2016, the Italian government banned shops from selling "kiddy packs," cigarettes in packs of ten. Tobacconists caught selling cigarettes to minors risk fines of up to 3000 euros or losing their licenses. The new legislation made it illegal to smoke in cars that carried children or pregnant women, prohibited smoking outdoors near schools and hospitals, and required more stringent labeling and packaging of cigarettes. The result of these policy efforts has seen a significant decline in smoking prevalence in Italy over time, suggesting that anti-smoking policies have been-at least partially-effective: in $199926.58 \%$ of adults aged 15 and older were active smokers compared with $23.18 \%$ in 2012 (Table 1). However, as in many other countries, specific policies aimed at reducing smoking inequalities in Italy are poor or non-existent. Our paper shows that the problem of smoking inequality is present and relevant in Italy, that socio-economic status, gender and education are major explicators of it, and that policymakers should focus their objectives not only on overall smoking prevalence, but also on reducing the consumption of tobacco within the lower socio-economic positions.

\section{Smoking-related inequalities}

Unhealthy lifestyles tend to be concentrated disproportionately among people in disadvantaged socioeconomic groups (Balia and Jones 2008), even besides the effects of smoking. This phenomenon may contribute to the persistence of health inequalities over time, in spite of efforts to improve health care access (Costa-Font 2014). Hence, approaches are needed which are more effective in improving lifestyles and, in particular, in reducing tobacco use, among disadvantaged groups and communities. The literature shows that as income declines, the likelihood of smoking rises (Laaksonen et al. 2005; Li and Guindon 2012), while the latter have more resources to care for their health than the former. In this way, smoking inequalities amplify health inequalities between different socio-economic positions.

Siahpush et al. (2002) highlight that Australian lone mothers smoke much more than coupled mothers. Smoking rates are higher amongst disadvantaged ethnic groups, such as aborigines in Oceania and blacks in North America, when compared to relevant white groups (Barbeau et al. 2004; Barnett et al. 2004). Blue-collar workers smoke more than white-collar workers (Sorensen et al. 2004; Green et al. 2007) and smoking is more prevalent among the low-educated compared to the highly educated (Green et al. 2007; Layte and Whelan 2009; Schaap and Kunst 2009). In many countries smoking prevalence in disadvantaged social groups has also increased over time (Khang and Cho 2006; Franks et al. 2007; Richter and Leppin 2007; Hiscock et al. 2012a; Nagelhout et al. 2012).

The relationship between smoking inequality at the individual level seems to be mediated by several factors. The literature shows that the choice of smoking is affected 


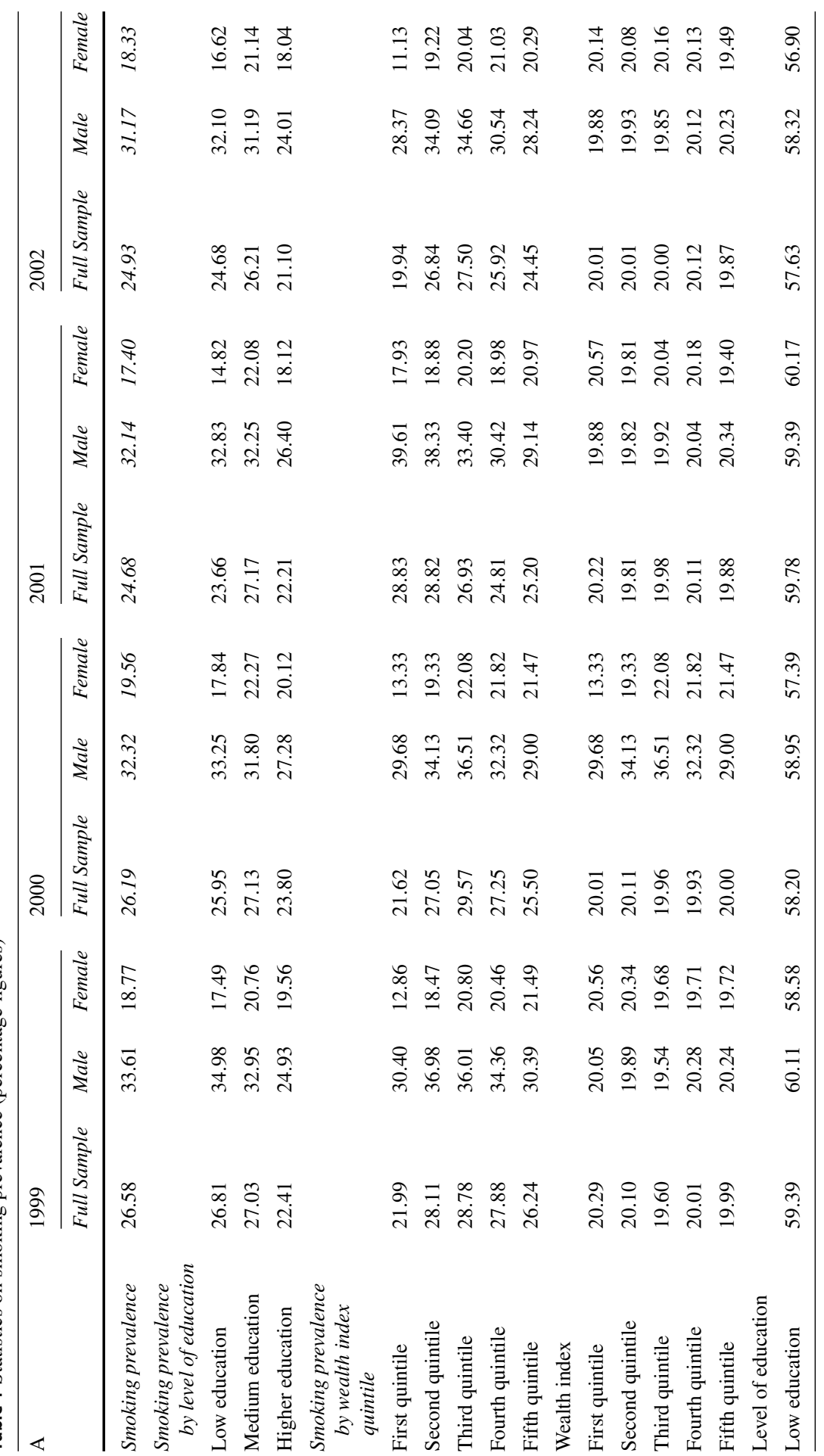




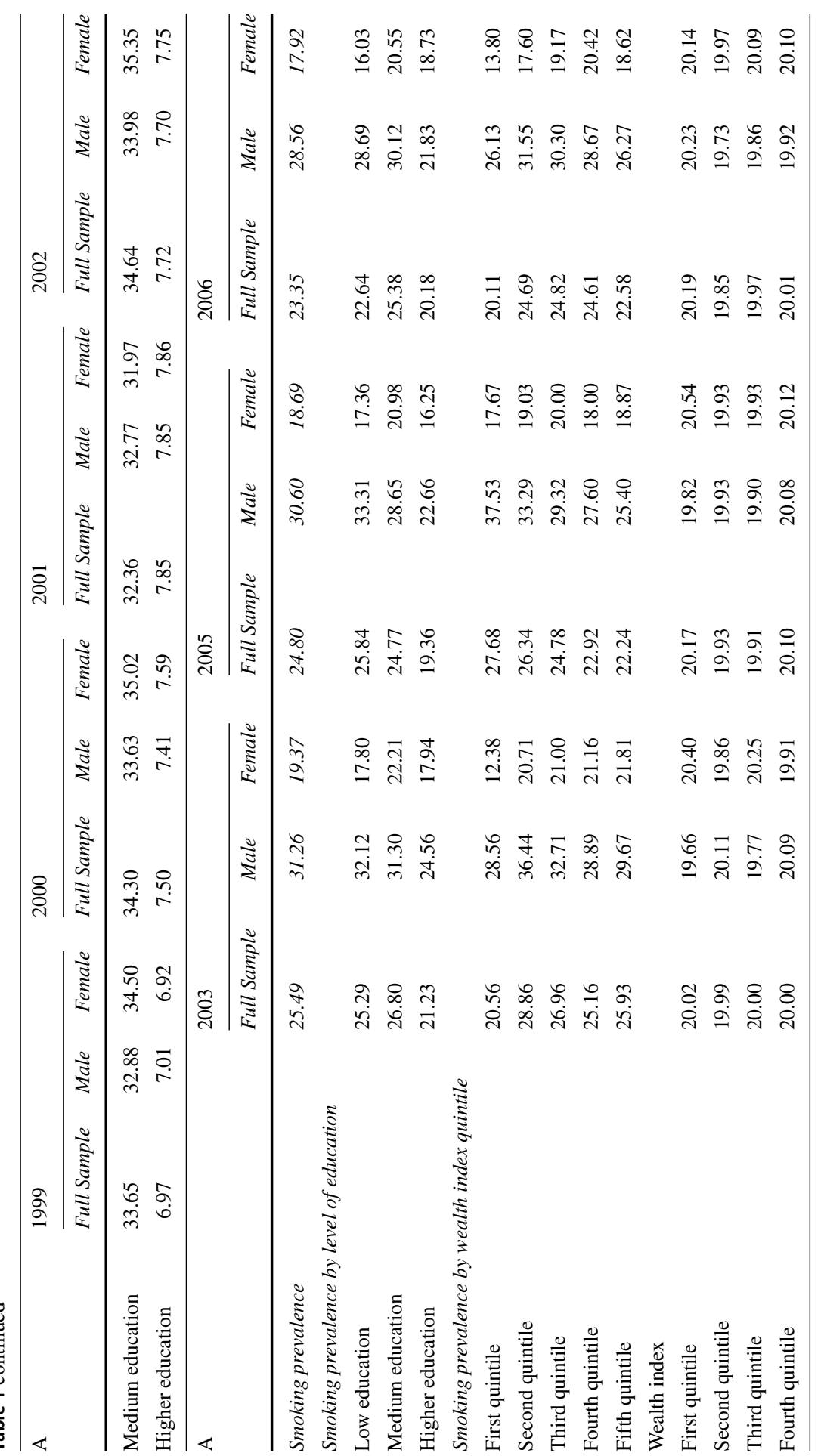




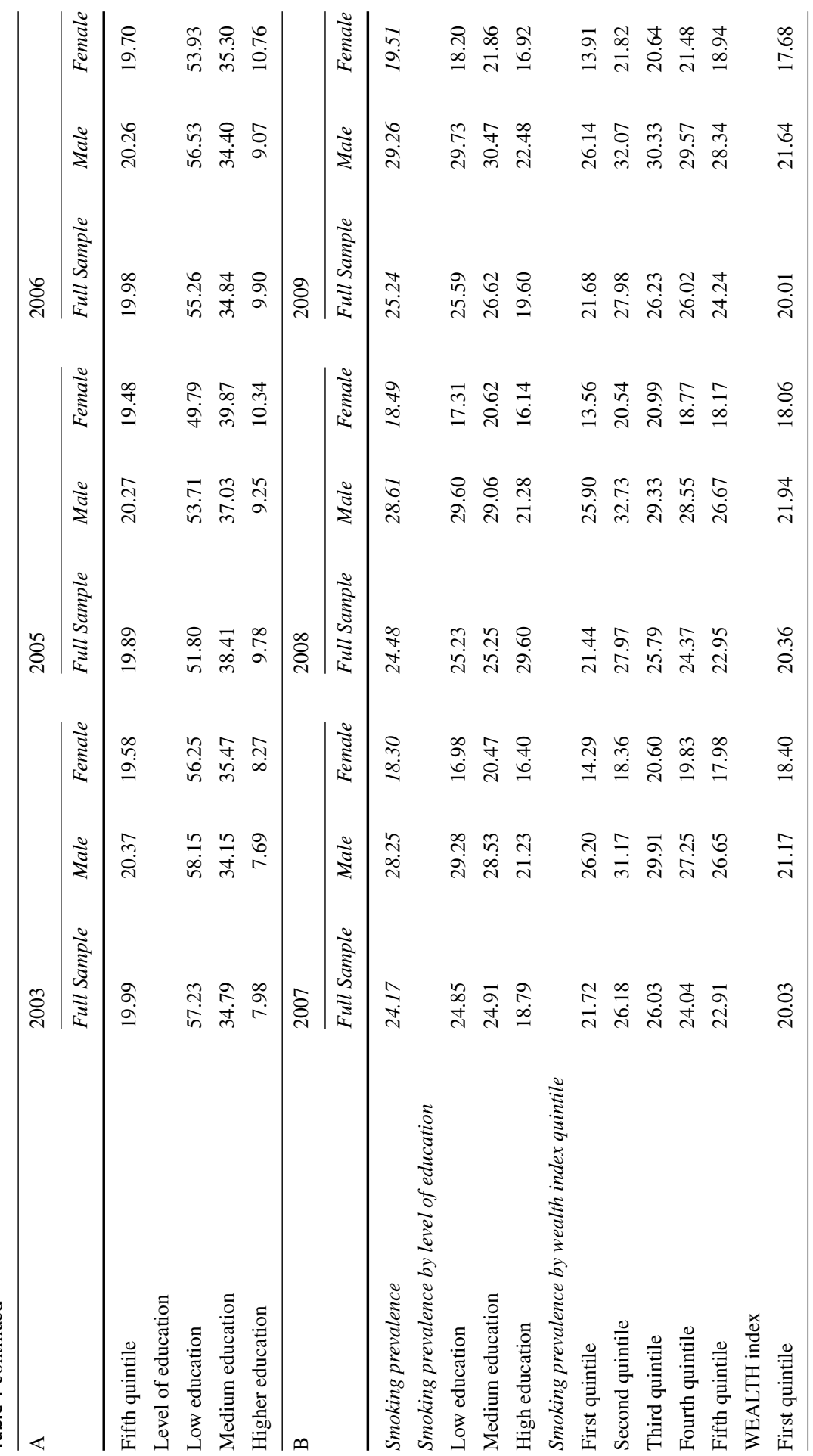




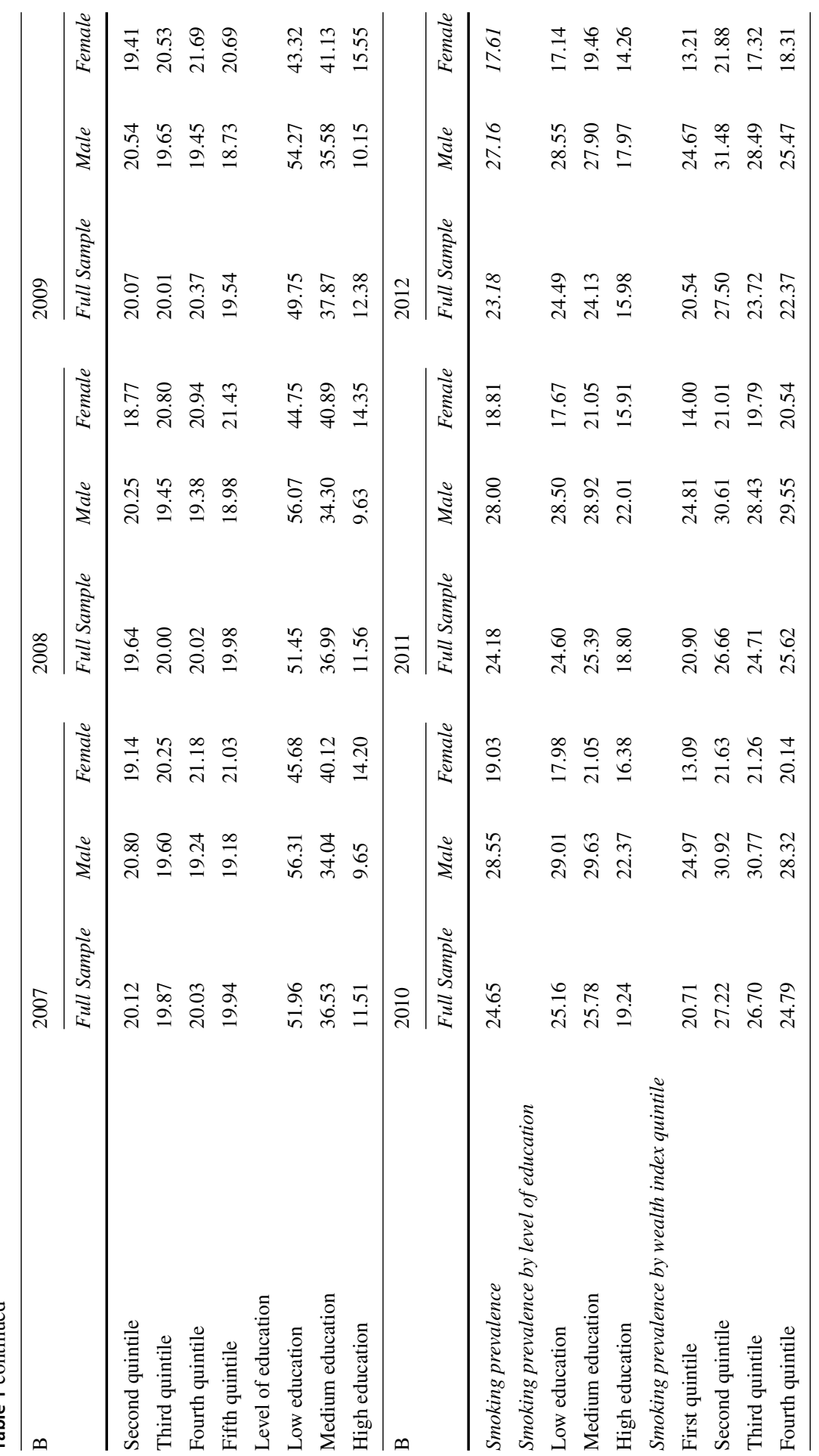




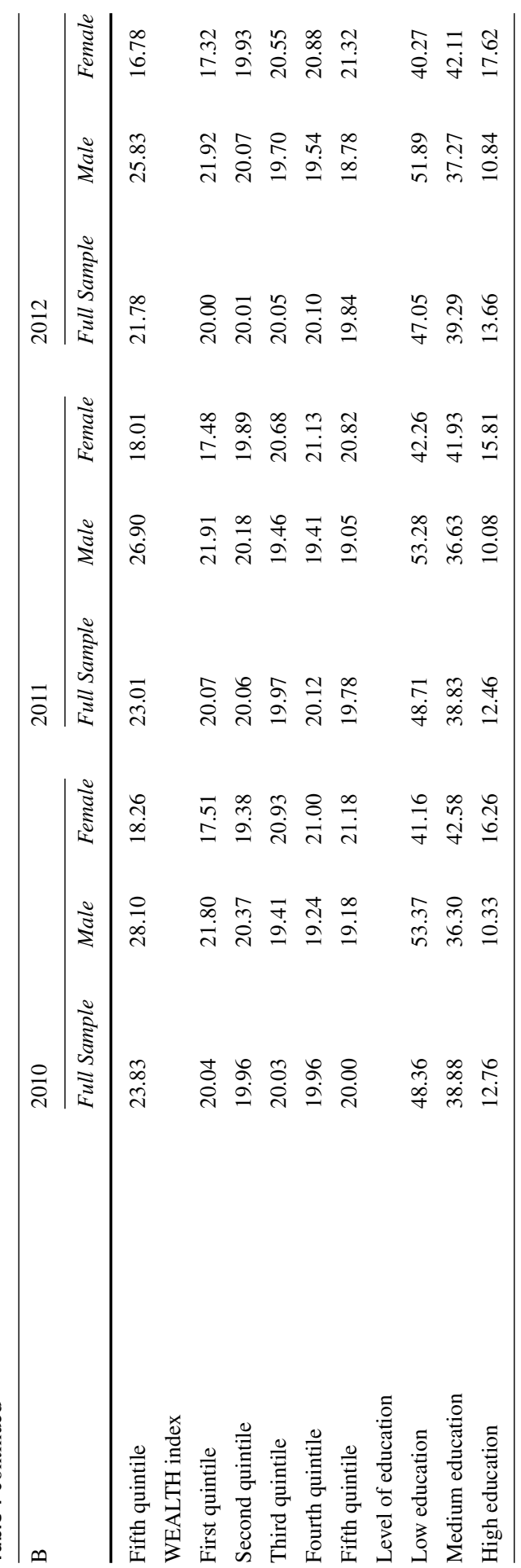


by variables such as gender, education, and employment status (Hiscock et al. 2012b; Di Novi and Marenzi 2019). For this reason, the study of individual-level data is particularly appropriate. Indeed, it allows us to capture the effect of factors such as gender and employment status, and to segment the population in different socio-economic positions according to socio-economic status and educational level of individuals. Indeed, while smokers may be found across all socio-economic positions and educational levels, they are not homogeneously distributed within the population. On the one hand, preferences for leisure activities outside home and in public places (such as eating in restaurants, drinking in bars and pubs, going to the cinema, visiting museums, etc.) are in contrast with those for smoking. On the other hand, people with higher education, higher income, and better and more stable career opportunities seem more prone to reduce smoking than others. The effect of these individual variables and that of leisure activities is clearly likely to increase inequalities. Disadvantaged people have less disposable income to spend on leisure activities, but bans forbid smoking in public places such as pubs, restaurants, etc., which the affluent frequent more than the poor.

Finally, smoking behaviour and smoking prevalence presents some gender-specific traits. On the one hand, smoking is generally more prevalent among men than women (Fukuda et al. 2005; Khang and Cho 2006; Bauer et al. 2007; Decicca et al. 2008; Anger et al. 2011; Hosseinpoor et al. 2012). Bauer et al. (2007) suggest that smoking behaviour differs substantially between men and women, and that education, marital and employment conditions explain a minor fraction of this difference (Khang et al. 2009 find similar results), suggesting the presence of a strong gender component in the choice of whether to smoke or not. Moreover, women from lower socio-economic positions generally smoke much less than women from higher socio-economic positions (Huisman et al. 2005). Some studies (e.g. Stehr 2007; Jacobs et al. 2009) show that women's demand for cigarettes is more price elastic than men's.

Not only do policies to reduce the use of tobacco generally not address the problem of inequality, but they might also be non-neutral with respect to it; for this reason a review of the main results that link policies and inequality is necessary. Studies on price increases are useful to understand the relative elasticity of the demand for tobacco derivatives between different social groups. Stehr (2007) finds that in the U.S.A. increases in taxes on tobacco had no effect on the quantity of cigarettes smoked by the most disadvantaged groups (Hispanics and Blacks), suggesting that -in this case - the price elasticity of demand for lower socio-economic groups is lower than for more advantaged groups. This result casts doubt on the effectiveness of anti-smoking measures such as tax increases to also support reductions in smoking inequalities. Franks et al. (2007) find that high-income people are more sensitive to the price of cigarettes than low-income individuals; in other words, increasing tax on tobacco exacerbates already existing smoking inequalities. However, Decicca et al. (2008) suggest that people are more sensitive to (anti-)smoking sentiments of their reference groups than to price increases. Smokers become addicted and their demand for nicotine is very inelastic; heavy taxation on tobacco is likely to reduce smoking initiation among the youth, but the effects appear modest, and the evidence is limited to a few advanced countries such as Canada (Sen and Wirjanto 2010). In other words, tobacco tax policies aimed at reducing overall consumption are likely to increase smoking inequalities. 
Another policy instrument for tobacco control has been bans and restrictions on tobacco consumption in different countries. Again we would anticipate a social gradient in response to this policy since the more educated would be more responsive to information about the risks associated with smoking. The result is that bans are more effective on high-income (and highly-educated) people. Khang et al. (2009) examine the effects of anti-smoking policies in South Korea and find that they have been effective in reducing the overall number of cigarettes smoked, but that, nevertheless, smoking inequalities have increased after the introduction of the restrictions. Moreover, for young people, education and familial background matter, since young people from affluent families perceive smoking as more risky than the young from poorer families. This has an impact on the decision to start smoking (Gerking and Khaddaria 2012); the consequence is that young people from disadvantaged families have a higher probability of starting (and continuing) to smoke.

Hill et al. (2014) have reviewed literature on the effect of tobacco control policies and highlight that taxes on tobacco products decrease the overall consumption, but there is evidence that generalised smoking cessation programmes (such as general bans) are found to increase smoking inequalities, as smokers from more advantaged socio-economic positions are more responsive to these bans. In some cases (Jones et al. 2015) studies find that bans do not reduce overall cigarette consumption e.g. Scotland's ban. This somewhat mixed evidence on the effects of anti-smoking policies such as smoking bans, highlights the importance of focusing on smoking inequalities and suggests that research and policy interventions in the field of tobacco control should address smoking inequality specifically.

\section{Data and methodology}

\subsection{Data}

We analyse the trend in smoking inequalities between 1999 and 2012 (the 2004 survey did not take place and hence was not included) employing individual-level data drawn from the cross-sectional survey "Indagine Multiscopo sulle Famiglie, Aspetti della Vita Quotidiana". This survey is part of the ISTAT Multiscopo survey system carried out every year by the Italian National Statistical Office (ISTAT), with a sample size of about 30,000 observations each year. Individual weights were applied in all computations in order to make the results representative of the Italian population. ${ }^{1}$

An assessment of the surveys was made in order to check their comparability and consistency. Given the repeated nature of the Multiscopo Survey, they were found to have more or less similar survey design, scope, coverage, sampling unit, reporting method, mode of survey and weighting method. Questionnaire wordings for most variables of interest were also found to be generally similar across the surveys. Where there were some differences with respect to some variables, efforts were made to align their definitions and/or categories as closely as possible across the surveys prior to

\footnotetext{
1 As common when using individual survey data, we use survey stratification weights provided by ISTAT in all our models. Survey stratification weights are defined during survey sampling by the provider of the data and are essential to make the analysis representative of the entire population.
} 
pooling the data. For example, if the categories of variables were different across the surveys, the categories were collapsed to a minimum number to make them consistent and comparable across the surveys.

\subsection{Smoking inequality index}

Our empirical analysis involves two basic steps. First, we explore the level of horizontal inequity smoking prevalence, employing the concentration index, and then we decompose the index into the contributions of demographic and socioeconomic factors.

Inequalities (and the potential inequities) in smoking prevalence are calculated by means of a concentration index (CI) (Wagstaff et al. 1991; Wagstaff and van Doorslaer 2000):

$$
C I=\frac{2}{n \mu} \sum_{i=1}^{n} y_{i} R_{i}-1=\frac{2}{\mu} \operatorname{cov}\left(y_{i}, R_{i}\right)
$$

where $\mu$ is the average smoking prevalence in the sample, $n$ the sample size, $Y$ is an indicator of smoking by individual $i$ and $\mathrm{R}_{\mathrm{i}}$ designates the $\mathrm{i}$-th individual's rank within the wealth index distribution. The value of the index is equal to the covariance between the smoking indicator $\left(\mathrm{Y}_{\mathrm{i}}\right)$ and the individual's living standard rank $\left(\mathrm{R}_{\mathrm{i}}\right)$, divided by the average of smoking prevalence $(\mu)$. Then, the whole expression is multiplied by 2 to ensure that it ranges between -1 and +1 (with -1 meaning that smoking is concentrated in the most disadvantaged person, and 1 indicating that smoking is concentrated in the most advantaged person. This index takes value 0 when smoking is perfectly equally distributed among the population). Since the variable that measures smoking prevalence is distributed between 0 and 1, as suggested by Erreygers (2009), we use a corrected version of the concentration index to compute inequality in smoking. This index is defined as:

$$
E(Y)=\frac{4 \mu}{\left(b_{n}-a_{n}\right)} C(Y)
$$

where $b_{n}$ and $a_{n}$ represent the maximum and the minimum of the smoking indicator variable $(Y)$ (in our case 0 and 1 ), $\mu$ is the mean of the smoking prevalence variable in the sample, and $C(Y)$ represents the concentration index specified in (1).

Wagstaff et al. (2003) have shown that it is possible to compute the concentration index also through a regression model using the OLS properties. Formally, for each regression model, the concentration index $\mathrm{E}(\mathrm{Y})$ can be rewritten as the sum of two components: the first as a deterministic one and the second as a residual one:

$$
E I(y)=4\left\lceil\beta_{r} \overline{x_{r}} C I_{r}+\sum_{k} \beta_{k} \overline{x_{k}} C I_{k}+G C I(\varepsilon)\right\rceil
$$


where $\bar{x}_{r}$ and $\bar{x}_{k}$ represent respectively the means of the living standard indicator used to rank the population $\left(\mathrm{x}_{\mathrm{r}}\right)$, and the regressors included in the regression model on which the computation of the concentration index is based. $\mathrm{CI}_{\mathrm{r}}, \mathrm{CI}_{\mathrm{k}}$ are their concentration indices while $\mathrm{GCI}(\varepsilon \mathrm{\varepsilon i})$ is a residual term.

Equation (3) shows that smoking inequality can be represented as a weighted sum of the inequalities in its determinants. The weights are represented by the regression coefficients evaluated at the means (i.e. semi-elasticities). The decomposition provides the possibility of identifying the driving factors of inequality in smoking prevalence. Decomposition of the concentration index as in Eq. (3) is based on linear modelling of smoking prevalence. However, since the outcome variable in our application is binary, following van Doorslaer et al. (2004), we base the decomposition on a linear approximation based on partial effects estimated by a non-linear model.

Hence, we estimated a model of the determinants of smoking behaviour through a probit model, where the dependent variable is binary and takes a value one if the respondent is a current smoker or zero if she is a former smoker or a non-smoker. Then, we used this model to compute and decompose the concentration index. In the probit model, we control for a set of explanatory variables such as age, sex, marital status, education, employment status, and a living standard index. Age is modelled as a continuous variable; sex is defined according to the dummy variable "male" that takes value one if respondents are male and zero otherwise (i.e. female is the reference category for sex). Marital status dummy variables include married (reference category), divorced/separated, widowed and never married. Three levels of education are considered: (1) low education (no educational certificates or primary school certificate or lower secondary education); (2) medium education (upper secondary education or high school graduation) (reference category) and (3) high education (university or postgraduate degree). Employment status is divided into six groups: employed (reference category), unemployed, retired, student, housewife, unable to work. ${ }^{2}$

In the "Indagine Multiscopo sulle Famiglie, Aspetti della Vita Quotidiana" direct numeric measures of welfare - such as household income-are not available; therefore, we use other proxies for household wealth. We derive a one-dimensional index of wealth from assets and living standards collected during the interviews, through principal component analysis (PCA) under the assumption that wealth is reflected in the assets owned and in the living conditions of the household. PCA was used to generate scoring weights for each variable: whether the interviewee owns the home where she lives, the number of rooms per household member, whether the house receives regular water supply, the presence of service staff and a battery of items on possessions in the home. The possessions include household items such as televisions, satellite dish, mobile phone, computer, internet access, hi-fi, camera, washing machine, dishwasher, air conditioning, and car (Vyas and Kumaranayake 2006; O’Donnel et al. 2008). For

\footnotetext{
2 We have tested for multicollinearity in the probit model employed to compute the Concertation Index (CI) by using the Variance Inflation Factor (VIF) and Tolerance(1/VIF). We find that VIF for all the independent variables included in the baseline model for the $\mathrm{CI}$ is quite low. Therefore, we can safely assume that there are no problems of multicollinearity.
} 
a detailed discussion of how to construct asset indices see Vyas and Kumaranayake $(2006)^{3}$

In order to measure smoking inequalities that reflect only non-demographic smoking differences, an indirectly standardised concentration index was computed. The concentration index has been standardised by age and gender to obtain an estimate of potentially avoidable inequality (see also O'Donnell et al. 2008). The standardisation allows for exploring whether lower socioeconomic groups are more likely to smoke than higher socioeconomic groups, keeping demographics constant. After standardisation, any residual inequality in smoking is interpretable as horizontal inequity (which could be pro-rich or pro-poor). Indirectly standardised smoking behaviour $\hat{Y}_{i}^{I S}$ can then be obtained by calculating the difference between actual smoking status $\left(\mathrm{Y}_{\mathrm{i}}\right)$ and standardised health status $\widehat{\left(Y_{i}^{X}\right)}$ plus the sample mean $(\bar{Y})$ :

$$
\hat{Y}_{i}^{I S}=Y_{i}-\hat{Y}_{i}^{X}+\bar{Y}
$$

Equation (4) represents the EDA (Erregeyers Demographic Adjusted) index and indicates that standardisation will subtract the variation in smoking behaviour driven by demographic factors from actual smoking status. Therefore, the distribution of $\hat{Y}_{i}^{I S}$ across wealth can be interpreted as the smoking status we expect to observe in an individual, irrespective of differences in the distribution of demographic characteristics. As smoking is unhealthy, a negative value of EDA indicates that smoking is concentrated among the poor (pro-rich inequality). If, instead, the value of the inequality index is positive, then smoking is concentrated among the most advantaged of the population (pro-poor inequality). We examine the correlation between the EDA index and the Italian GDP lagged by one year to assess whether smoking increases during economic downturns, (Kendzor et al. 2010), and whether-because of budget constraints-people with high incomes tend to relapse smoking more than people with low incomes during periods of financial strain (McClure et al. 2012).

We also split the sample by gender and conduct the same analysis on the two sub-samples. All estimations are carried out with STATA 14. For details on the computational issues (using STATA) we refer to O’Donnel et al. (2008).

\section{Results}

Table 1 shows the smoking prevalence over the years of observations according to gender, wealth index quintiles and education (which is one of the crucial measures of socioeconomic status in explaining smoking habits). Table 1 highlights two traits of smoking behaviour for males and females: first, males are more likely to smoke than females are. Second, a higher level of wealth and a higher level education are associ-

\footnotetext{
${ }^{3}$ We also rescaled the wealth index by adding a constant of 4.2 , which was the minimum whole number required to eliminate negative values. The range of the asset index prior to rescaling in 2012 year of observation, for instance, was -4.197 to 1.565 . After rescaling, the range was 0.003 to 5.765 . This rescaling does not affect the contribution of each variable to the concentration index, since the rank ordering is unchanged. However, the relative magnitude of the contribution and concentration index in the decomposition does change.
} 
Table 2 Smoking inequality among the overall Italian adult population

Negative values of EDA index mean that smoking is prevalent among the poor

EDA index ranges from -1

(only the poorest smoke) to 1

(only the richest smoke)

Significance levels: $* 10 \%$,

$* * 5 \%$, *** $1 \%$

\begin{tabular}{llllll}
\hline & 1999 & 2000 & 2001 & 2002 & 2003 \\
\hline EDA index & -0.009 & -0.003 & 0.004 & -0.021 & -0.023 \\
Standard error & 0.005 & 0.005 & 0.006 & 0.005 & 0.006 \\
Significance & $*$ & & & $* * *$ & $* * *$ \\
& 2005 & 2006 & 2007 & 2008 & 2009 \\
EDA index & -0.021 & -0.030 & -0.034 & -0.036 & -0.018 \\
Standard error & 0.006 & 0.006 & 0.006 & 0.005 & 0.006 \\
Significance & $* * *$ & $* * *$ & $* * *$ & $* * *$ & $* * *$ \\
& & 2010 & 2011 & 2012 & \\
EDA index & & -0.014 & -0.020 & -0.036 & \\
Standard error & & 0.007 & 0.005 & 0.005 & \\
Significance & & $* *$ & $* * *$ & $* * *$ & \\
\hline
\end{tabular}

ated with lower smoking prevalence among males but not among females; smoking prevalence has declined over time but the decline has been steeper for males compare to females.

We present first the inequality index for the full sample, and then those disaggregated by gender. Table 2 reveals the aggregated $E D A$ index is almost always negative, highlighting that smoking inequality tends to be pro-rich (i.e. concentrated amongst the poor). The trend of the index suggests that the magnitude of the inequality has increased over time, but this increase has not been constant. According to our results and Table 1, those who are highly educated and affluent (fourth and fifth quintiles of the wealth index) show higher smoking prevalence between 2008 and 2010 than before. In such a way, the gap between the rich and the poor narrows and so does smoking socio-economic inequality.

If we couple these figures with the variation of the Italian GDP lagged by one year, we notice that the two variables present a relatively high and statistically significant correlation (correlation coefficient: 0.581 ; p-value: 0.078 ). This is an interesting result, as it suggests that smoking inequality in Italy co-varies with GDP. This suggests that in times of recession, a small number of poor and a relatively large number of rich people relapse smoking, while the opposite happens when the economy grows.

Table 3 shows a disaggregation of the EDA index, according to individual characteristics (in particular, socio-economic status, level of education and employment status). Starting with the wealth index, we notice that its contribution is mixed: in some years, it is statistically significant with a negative sign; in others, it is not statistically significant, and sometimes it has a positive sign and is statistically significant.

Considering education, we notice almost no trend: the signs of the contributions of high and low education remain negative. This indicates that low and high levels of education are associated with higher pro-rich inequality. In addition, the magnitude of these contributions is relatively stable over the years. Together with the results for the wealth index, these findings suggest that overall, education is more relevant in shaping smoking behaviour than wealth is. 


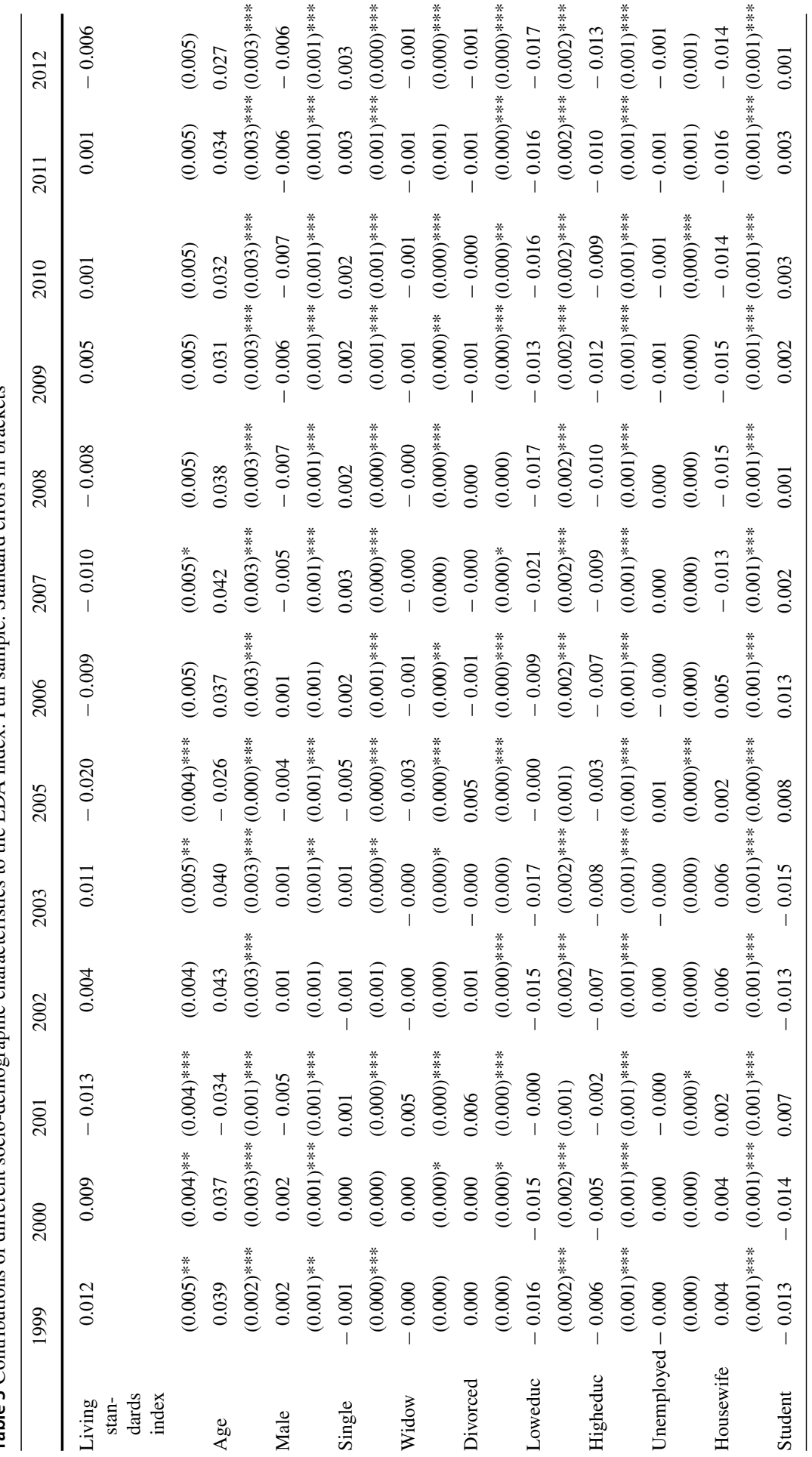







Table 4 Smoking inequality: male subsample

Negative values of EDA index mean that smoking is prevalent among the poor

EDA index ranges from -1

(only the poorest smoke) to 1

(only the richest smoke)

Significance levels: $* 10 \%$,

$* * 5 \%$, *** $1 \%$

\begin{tabular}{llllll}
\hline & 1999 & 2000 & 2001 & 2002 & 2003 \\
\hline EDA index & -0.046 & -0.048 & -0.060 & -0.075 & -0.074 \\
Standard error & 0.007 & 0.007 & 0.006 & 0.007 & 0.007 \\
Significance & $* * *$ & $* * *$ & $* * *$ & $* * *$ & $* * *$ \\
& 2005 & 2006 & 2007 & 2008 & 2009 \\
EDA index & -0.065 & -0.073 & -0.056 & -0.052 & -0.034 \\
Standard error & 0.006 & 0.007 & 0.006 & 0.006 & 0.006 \\
Significance & $* * *$ & $* * *$ & $* * *$ & $* * *$ & $* * *$ \\
& & 2010 & 2011 & 2012 & \\
EDA index & & -0.015 & -0.056 & -0.063 & \\
Standard error & & 0.006 & 0.007 & 0.008 & \\
Significance & & $* * *$ & $* * *$ & $* * *$ & \\
\hline
\end{tabular}

Smoking inequality tends to decrease with age, and also in this case we do not observe any relevant change over time. The contribution of male gender to pro-rich inequality is mainly negative (i.e. inequality is slightly lower among men than among women) before 2005, but becomes steadily positive after. This may suggest that the ban, which came into effect in 2005, might have had different effects on men and women, and indeed the results below show that these differ by gender.

Tables 4 and 5 present the same analysis as in Tables 2 and 3, but restricting the sample to males. We first focus on the EDA index: it takes negative and statistically significant values over the entire period considered. This means that inequality is present among males and that smoking is more prevalent among the poor than the wealthy. This result is in line with that for the full sample. We also observe a constant increase of the EDA index until 2006, in particular after 2008 the value of the index is decreasing consistently until 2011 and 2012, with the effects of the economic recession on smoking inequality previously mentioned.

Focusing our attention on the contributors to the male inequality result, we notice that the wealth index and the age of the individual are the most relevant variables. They are both statistically significant over the entire period and have (almost) always opposite signs. On the one hand, the living standard index has the same sign as the EDA index, suggesting that smoking is prevalent among people from disadvantaged socioeconomic positions. However, during the last two periods considered, the contribution of the wealth index reduces substantially, in line with that observed before. Age has a positive sign in most of the years. This result suggests that inequality decreases with age. In other words, smoking is prevalent among the younger disadvantaged socio-economic positions.

As in the case of the full sample, inequality is prevalent among low- and higheducated males compared to those with an intermediate level of education. Among students, inequality is pro-rich (negative sign) before 2005, and becomes pro-poor (positive sign) afterwards. Although the magnitude of the contribution is small, the reversal of the sign is statistically significant and interesting. This effect may be due to the smoking ban enforced since 2005; this ban may have discouraged smoking 


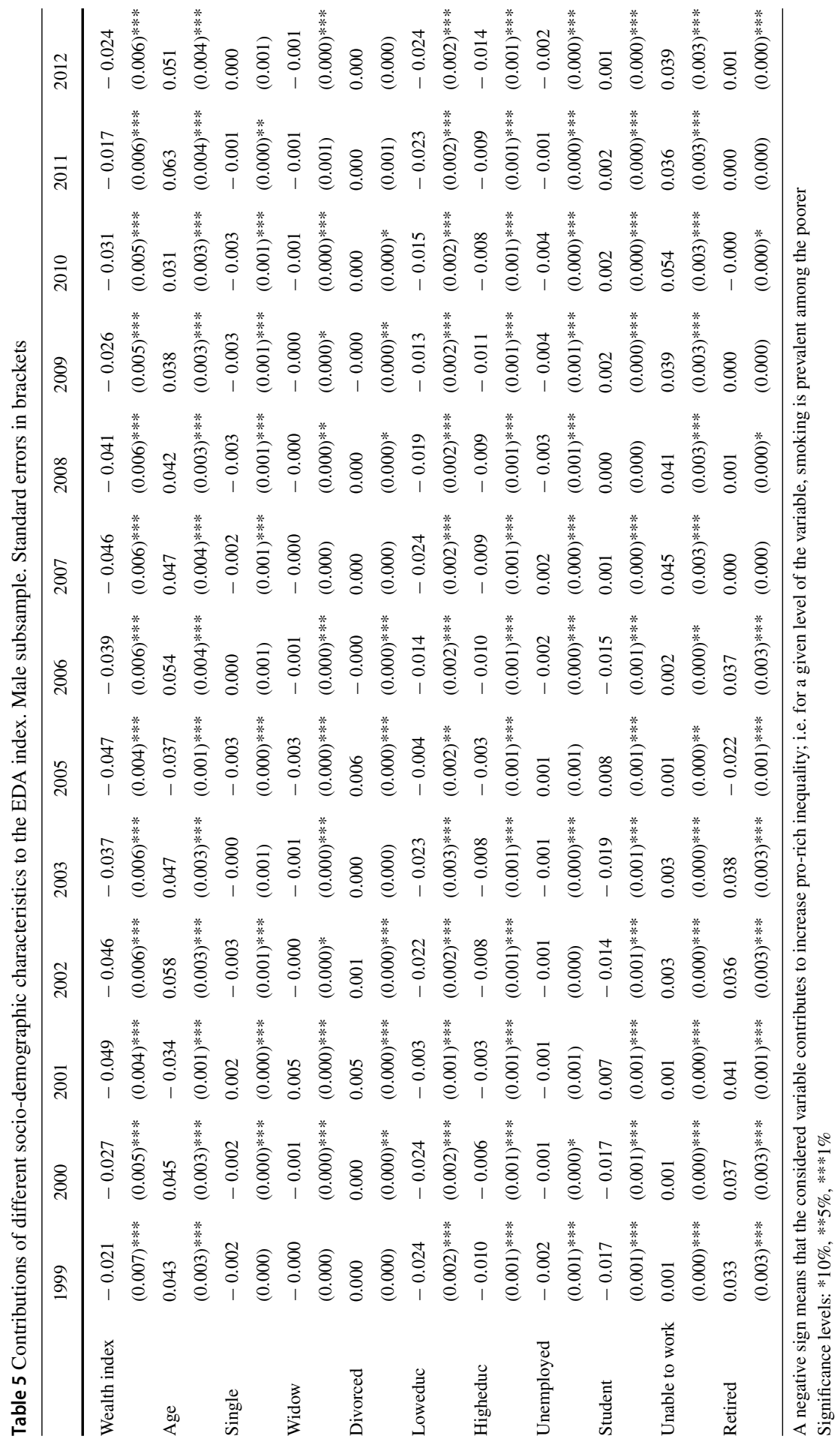


Table 6 Smoking inequality: female subsample

Negative values of EDA index mean that smoking is prevalent among the poor

EDA index ranges from -1

(only the poorest smoke) to 1

(only the richest smoke)

Significance levels: $* 10 \%$,

$* * 5 \%$, *** $1 \%$

\begin{tabular}{llllll}
\hline & 1999 & 2000 & 2001 & 2002 & 2003 \\
\hline EDA index & 0.035 & 0.045 & 0.054 & 0.035 & 0.031 \\
Standard error & 0.006 & 0.005 & 0.006 & 0.005 & 0.005 \\
Significance & $* * *$ & $* * *$ & $* * *$ & $* * *$ & $* * *$ \\
& 2005 & 2006 & 2007 & 2008 & 2009 \\
EDA index & 0.012 & 0.014 & 0.021 & 0.016 & 0.027 \\
Standard error & 0.005 & 0.005 & 0.006 & 0.006 & 0.006 \\
Significance & $* *$ & $* * *$ & $* * *$ & $* *$ & $* * *$ \\
EDA index & & 2010 & 2011 & 2012 & \\
Standard error & & 0.013 & 0.024 & -0.006 & \\
Significance & & 0.008 & $(0.005)$ & $(0.006)$ & \\
\hline
\end{tabular}

among students from the poorer socio-economic positions, contributing to mitigate inequality. Since students are young, if this change in behaviour were to persist as these individuals age, then we would observe a reduction in the pro-rich smoking inequality in future years. Being unemployed decreases inequality, and the effect is particularly strong since 2007 . This result may be due to the tight budget constraints that affect people who do not work; the effect is stronger after 2007, perhaps as a consequence of the international economic crisis, which has impacted the lower socio-economic positions more than others. In this way, the result has been a reduction in the prorich smoking inequality, where the poorer the individual, the higher the probability of giving up smoking.

Tables 6 and 7 present the results for the female subsample. Here, the figures tell us a story that is completely different from that seen so far. Smoking inequality among women is pro-poor: the EDA index is indeed positive and statistically significant, indicating that smoking is more prevalent among affluent than among poor women. Moreover, pro-poor inequality in the female sub-sample decreases after the introduction of the smoking ban in Italy, suggesting that it was more effective in reducing smoking prevalence in the upper than in the lower socio-economic positions. The contribution of the wealth index always has a positive sign, meaning that wealth increases the level of pro-poor inequality among women.

\section{Conclusions}

The results presented in this paper show relevant differences between men and women in smoking inequalities. Among men, inequality is pro-rich, while the opposite is true among women.

This result is in line with the cited literature and seems to be a (perverse) result of the process of female emancipation. The negative stereotype of smoking women has been abandoned over time, and smoking has become a symbol of liberation of the female gender (Tinkler 2003, 2006; Hunt et al. 2004). It has led to gender dif- 


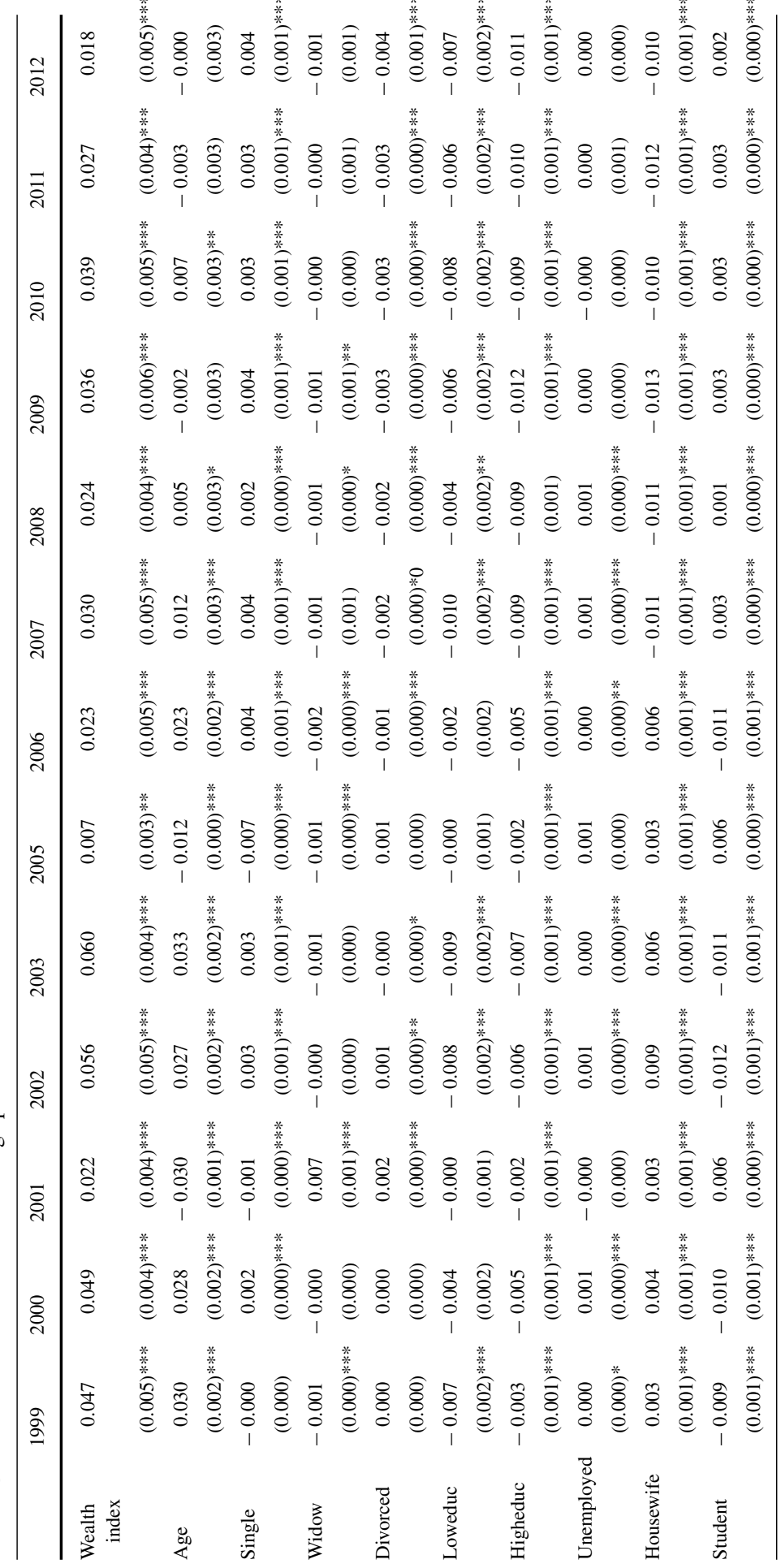




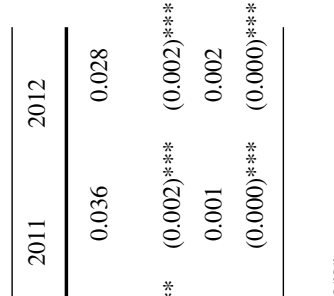



$$
\begin{aligned}
& \text { 尊 }
\end{aligned}
$$





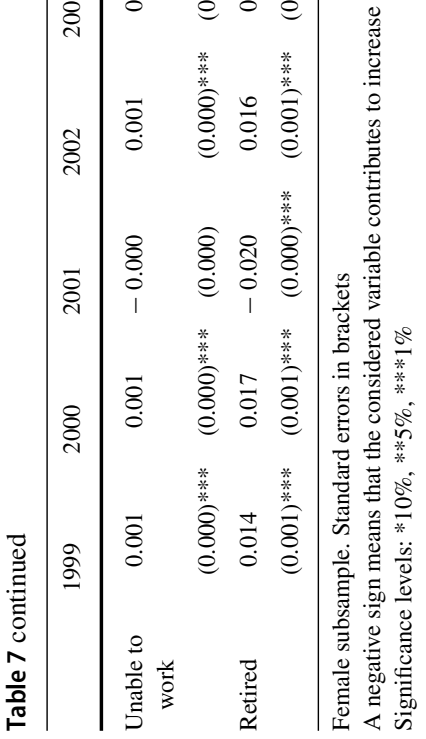


ferences in smoking initiation disappearing in contemporary young generations (Sen and Wirjanto 2010). In some countries, smoking is even more prevalent among girls than among boys (Li and Guindon 2012). As often happens, affluent socio-economic positions emancipate faster and earlier than lower socio-economic positions. However, the introduction of the ban seems to have reduced inequality among females. On the one hand, women are generally more sensitive to prevention and to health campaigns than men (Vlassoff and Garcia-Moreno 2002), and this sensitivity is stronger among the rich than among the poor. On the other hand, if smoking is a sign of emancipation, women may want to signal their freedom by smoking in public. Assuming that affluent women are more emancipated than poor women, the policies aimed at restricting smoking both by anti-smoking programmes and by banning it in public places are likely to have reduced smoking more in the affluent than in the lower socio-economic positions. This result is particularly worrying, as health is generally better in the upper than in the lower socio-economic positions. Therefore, a reduction in smoking prevalence mainly in high socio-economic positions will likely widen the health gap between rich and poor women. In this sense, the ban introduced in 2005 not only seems ineffective in reducing inequality, but its effects appear even perverse.

The results of the paper should be read also within the phenomenon of the smoking transition.Lopez et al. (1994) show two patterns of smoking that are relevant in the present case: on the one hand, as an epidemic, smoking prevalence in a population first increases, then peaks and eventually starts reducing slowly. The second interesting result is that, while prevalence among women is lower than among men in all the stages of the epidemic, the difference between the two genders narrows over time, becoming, at the end of the cycle described by the authors, near to zero. This happens, as the peak for women follows that for men, and prevalence among women reduces slowly than among men. Such a phenomenon is consistent with the results presented in this paper, suggesting that Italy is in phase 3 (for women) and 4 (for men) of the model proposed by Lopez et al. (1994). ${ }^{4}$ Moreover, the results presented in this paper seem to confirm what Cavellaars et al. (2000) found for Southern European countries.

This paper contributes to the literature in a number of ways. First, it shows that smoking inequality follows the economic cycle. Financial strain during economic downturns may affect smoking behaviour, inducing individuals to ameliorate the effects of feeling anxiety by more frequently enacting behaviours which give temporary relief such as smoking. However, the effects of population-level financial strain on smoking can also differ amongst those of differing socio-economic levels, sometimes affecting inequalities. In Italy, while the national prevalence of smoking had increased between 2009 and 2010 compared with 2008 (ISTAT, Health for All 2017) possibly due to the economic crisis and to the relapsing of former smokers (Gallus et al. 2011), inequality in

\footnotetext{
4 According to ISTAT data (Health for All 2019) smoking prevalence for women peaked in the 1980s, and prevalence has been declining particularly among the affluent. Nevertheless, inequality is still pro-poor (positive sign in Table 6). Prevalence among men peaked instead at the end of the 1960s, and then started declining, before in the affluent groups, and then in the poor. Men have therefore reached phase 4 of Lopez (1994) model, and inequality is nowadays prorich.
} 
smoking prevalence has decreased, supporting the idea that people with high income tend to relapse smoking more than people with low income.

Second, the paper shows that smoking inequality is gender-driven across different socio-economic positions. Our findings suggest that smoking policies should target men and women differently. Moreover, as men are less sensitive than women to health campaigns and to smoking bans, governments should spend more resources on convincing men to stop smoking. Welfare policies aimed at protecting the most disadvantaged socio-economic positions could have also the (ancillary) effect of reducing smoking inequality (among women), although this outcome works in the direction of increasing the overall health inequality between rich and poor.

We conclude by highlighting the importance of enacting policies targeted at socioeconomic positions that are particularly vulnerable to smoking. Such policies will have to account for the heterogeneity between genders and socio-economic positions highlighted in this paper, e.g. focusing messages through specific channels and in delivered in ways which target different socio-economic groups. Of course, we acknowledge that this heterogeneity is a challenge for the legislator; nevertheless, the positive externalities in terms of individual and public health expected from a decrease in smoking inequality should convince policymakers to intervene. We also highlight that, in the period considered by the analysis, while smoking inequality has varied over time, wealth and income inequalities have not (see the Table in the Appendix A1), suggesting that a reduction in smoking inequality may be pursued separately from the objective of reducing other types of inequality.

Funding Open access funding provided by Università degli Studi di Torino within the CRUI-CARE Agreement.

Open Access This article is licensed under a Creative Commons Attribution 4.0 International License, which permits use, sharing, adaptation, distribution and reproduction in any medium or format, as long as you give appropriate credit to the original author(s) and the source, provide a link to the Creative Commons licence, and indicate if changes were made. The images or other third party material in this article are included in the article's Creative Commons licence, unless indicated otherwise in a credit line to the material. If material is not included in the article's Creative Commons licence and your intended use is not permitted by statutory regulation or exceeds the permitted use, you will need to obtain permission directly from the copyright holder. To view a copy of this licence, visit http://creativecommons.org/licenses/by/4.0/. 


\section{Appendix: Time trends of aggregate inequality in Italy}

Table A1 Aggregate inequality over time in Italy

\begin{tabular}{lll}
\hline Year & $\begin{array}{l}\text { Concentration Index for Wealth (Authors } \\
\text { estimate) }\end{array}$ & GINI index (World Bank estimate) \\
\hline 1999 & 0.141 & - \\
2000 & 0.142 & 0.353 \\
2001 & 0.096 & - \\
2002 & 0.143 & - \\
2003 & 0.142 & 0.349 \\
2005 & 0.088 & 0.338 \\
2006 & 0.142 & 0.337 \\
2007 & 0.141 & 0.329 \\
2008 & 0.140 & 0.338 \\
2009 & 0.132 & 0.338 \\
2010 & 0.138 & 0.347 \\
2011 & 0.129 & 0.351 \\
2012 & 0.136 & 0.352 \\
\hline
\end{tabular}

\section{References}

Anger, S., Kvasnicka, M., \& Siedler, T. (2011). One last puff? Public smoking bans and smoking behavior. Journal of Health Economics, 30(3), 591-601.

Baker, E. H. (2014). “Socioeconomic Status, Definition” in The Wiley-Blackwell Encyclopedia of Health, Illness, Behavior, and Society. Hoboken: Wiley.

Balia, S., \& Jones, A. M. (2008). Mortality, lifestyle and socio-economic status. Journal of Health Economics, 27, 1-26.

Bambra, C., Gibson, M., Sowden, A., Wright, K., Whitehead, M., \& Petticrew, M. (2016). Tackling the wider social determinants of health and health inequalities: Evidence from systematic reviews. Journal of Epidemiology and Community Health, 64, 284-291.

Barbeau, E., Krieger, N., \& Soobader, M.-J. (2004). Working class matters: Socioeconomic disadvantage, rece/ethnicity, gender, and smoking in NHIS 2000. American Journal of Public Health, 94(2), 269-280.

Barnett, R., Moon, G., \& Kearns, R. (2004). Social inequalities and ethnic differences in smoking in New Zealand. Social Science \& Medicine, 59, 129-143.

Bauer, T., Göhlmann, S., \& Sinning, M. (2007). Gender differences in smoking behavior. Health Economics, 16(9), 895-909.

Brown, T., Platt, S., \& Amos, A. (2014). Equity impact of European individual-level smoking cessation interventions to reduce smoking in adults: A systematic review. European Journal of Public Health, 24(4), 551-556.

Cavelaars, A. E. J. M., Kunst, A. E., Geurts, J. J. M., Crialesi, R., Grödvedt, L., Helmert, U., et al. (2000). Educational differences in smoking: International comparison. British Journal of Medicine, 320, 1102-1107. 
Contoyannis, P., \& Jones, A. M. (2004). Socio-economic status, health and lifestyle. Journal of Health Economics, 23, 965-995.

Cornelsen, L., \& Normand, C. (2012). Impact of the smoking ban on the volume of bar sales in Ireland-evidence from time series analysis. Health Economics, 21(5), 551-561.

Decicca, P., Kenkel, D., Mathios, A., Shin, Y.-J., \& Lim, J.-Y. (2008). Youth smoking, cigarette prices, and anti-smoking sentiment. Health Economics, 17(6), 733-749.

Di Novi, C. (2010). The influence of traffic-related pollution on individuals' life-style: Results from the BRFSS. Health Economics, 19, 1318-1344.

Novi, Di, \& Cinzia. (2013). The indirect effect of fine particulate matter on health through individuals' life-style. Journal of Socioeconomics, 44, 27-36.

Di Novi, C., \& Marenzi, A. (2019). The smoking epidemic across generations, gender, and educational groups: A matter of diffusion of innovations. Economics and Human Biology, 33, 155-168.

Dixon, J., \& Banwell, C. (2009). Theory driven research design for explaining behavioural health risk transitions: The case of smoking. Social Science \& Medicine, 68, 2206-2214.

Erreygers, G. (2009). Correcting the concentration index. Journal of Health Economics, 28, 504-515.

Franks, P., Jerant, A. F., Paul Leigh, J., Lee, D., Chiem, A., Lewis, I., et al. (2007). Cigarette prices, smoking and the poor: Implications of recent trends. American Journal of Public Health, 97(10), 1873-1878.

Fukuda, Y., Nakamura, K., \& Takano, T. (2005). Socioeconomic pattern of smoking in Japan: Income inequality and gender and age differences. Annals of Epidemiology, 15(5), 365-372.

Gallup Organization. (2009). Survey on Tobacco. Analytical Report, Flash EB no 253.

Gallus, S., Tramacere, I., Pacifici, R., Zuccaro, P., Colombo, P., Ghislandi, S., et al. (2011). Smoking in Italy 2008-2009: A rise in prevalence related to the economic crisis? [Letter to the Editor]. PrevMed, 52(2), 182-183.

Gerking, S., \& Khaddaria, R. (2012). Perceptions of health risk and smoking decisions of young people. Health Economics, 21(7), 865-877.

Green, M. P., McCausland, K. L., Xiao, H., Duke, J. C., Vallone, D. M., \& Healton, C. G. (2007). A closer look at smoking among young adults: Where tobacco control should focus its attention. American Journal of Public Health, 97(8), 1427-1434.

Hill, S., Amos, A., Clifford, D., \& Platt, S. (2014). Impact of tobacco control interventions on socioeconomic inequalities in smoking: Review of the evidence. Tobacco Control, 23(1), e89-e97.

Hiscock, R., Bauld, L., Amos, A., \& Platt, S. (2012a). Smoking and socioeconomic status in England: The rise of the never smoker and the disadvantaged smoker. Journal of Public Health, 34(3), 390-396.

Hiscock, R., Bauld, L., Amos, A., Fidler, J. A., \& Munafò, M. (2012b). Socioeconomic status and smoking: A review. Annals of the New York Academy of Sciences, 1248, 107-123.

Hosseinpoor, A. R., Parker, L. A., d'Espaignet, E. T., \& Chatterji, S. (2012). Socioeconomic Inequality in Low-Income and Middle-Income Countries: Results from the World Health Survey. PLoS ONE, 7(8), $1-8$.

Huisman, M., Kunst, A. E., \& Mackenbach, J. P. (2005). Inequalities in the Prevalence of Smoking in the European Union: Comparing Education and Income. Preventive Medicine, 40(6), 756-764.

Hunt, K., Hannah, M.-K., \& West, P. (2004). Contextualizing smoking: Masculinity, femininity and class differences in smoking in men and women from three generations in the West of Scotland. Health Education Research, 19(3), 239-249.

Jacobs, R., Chaloupka, F. J., Tauras, J. A., Waters, H., \& Yurekli, A. (2009). Taxation and the economics of tobacco control. In J. M. Samet \& S. Y. Yoon (Eds.), Gender, women and the tobacco epidemic: Challenges for the 21st century (pp. 207-230). Geneva: WHO.

Jones, A. M., Laporte, A., Rice, N., \& Zucchelli, E. (2015). Do public smoking bans have an impact on active smoking? Evidence from the UK. Health Economics, 24(2), 175-192.

Kendzor, D. E., Businelle, M. S., Costello, T. J., Castro, Y., Reitzel, L. R., Cofta-Woerpel, L. M., et al. (2010). Financial strain and smoking cessation among racially/ethnically diverse smokers. American Journal of Public Health, 100(4), 702-706.

Khang, Y.-H., \& Cho, H.-J. (2006). Socioeconomic inequality in cigarette smoking: Trends by gender, age, and socioeconomic position in South Korea, 1989-2003. Preventive Medicine, 42(6), 415-422.

Khang, Y.-H., Yun, S.-C., Cho, H.-J., \& Jung-Choi, K. (2009). The impact of Governmental Antismoking Policy on socioeconomic disparities in cigarette smoking in South Korea. Nicotine \& Tobacco Research, 11(3), 262-269.

Laaksonen, M., Rahkonen, O., Karvonen, S., \& Lahelma, E. (2005). Socioeconomic status and smoking. European Journal of Public Health, 15(3), 262-269. 
Layte, R., \& Whelan, C. T. (2009). Explaining social class inequalities in smoking: The role of education, self-efficacy, and deprivation. European Sociological Review, 25(4), 399-410.

Li, D. X., \& Emmanuel Guindon, G. (2012). Income, income inequality and youth smoking in low- and middle-income countries. Addiction, 108, 799-808.

Lopez, A. D., Collishaw, N. E., \& Piha, T. (1994). A Descriptive model of the cigarette epidemic in developed countries. Tobacco Control, 3, 242-247.

Mackenbach, J. P. (2006). Health inequalities: Europe in profile. London: H.M. Government, Department of Health and Social Care.

McClure, C. B., Vladimarsdóttir, U. A., Hauksdóttir, A., \& Kawachi, I. (2012). Economic crisis and smoking behaviour: Prospective Cohort Study in Iceland. British Medical Journal Open, 2(5), 1-7.

Nagelhout, G. E., de Korte de BoerKunst, D. A. E., van der Meer, R. M., van Gelder, B. M., \& Willemsen, M. C. (2012). Trends in socioeconomic inequalities in smoking, consumption, initiation and cessation between 2001 and 2008 in the Netherlands. Findings from a National Population Survey. BMC Public Health, 12, 2-9.

Pampel, F. C. (2005). Diffusion, cohort change, and social patterns of smoking. Social Science Resources, 34, 117-139.

Pieroni, L., Chiavarini, M., Minelli, L., \& Salmasi, L. (2013). The role of anti-smoking legislation on cigarette and alcohol consumption habits in Italy. Health Policy, 111(2), 116-126.

Richter, M., \& Leppin, A. (2007). Trends in socio-economic differences in tobacco smoking among German Schoolchildren, 1994-2002. European Journal of Public Health, 17(6), 565-571.

Rogers, E. M. (2003). Diffusion of innovations. New York: Free Press.

Schaap, M. M., \& Kunst, A. E. (2009). Monitoring of socio-economic inequalities in smoking: Learning from the experiences of recent scientific studies. Public Health, 123(1), 103-109.

Sen, A., \& Wirjanto, T. (2010). Estimating the impacts of cigarette taxes on youth smoking participation, initiation, and persistence: Empirical evidence from Canada. Health Economics, 19(11), 1264-1280.

Siahpush, M., Borland, R., \& Scollo, M. (2002). Prevalence and socio-economic correlates of smoking among lone mothers in Australia. Australian and New Zealand Journal of Public Health, 26(2), 132-135.

Sorensen, G., Barbeau, E., Hunt, M. K., \& Emmons, K. (2004). Reducing social disparities in tobacco use: A social-contextual model for reducing tobacco use among blue-collar workers. American Journal of Public Health, 94(2), 230-240.

Stehr, M. (2007). The effect of cigarette taxes on smoking among men and women. Health Economics, 16(12), 1333-1343.

Tinkler, P. (2003). Refinement and respectable consumption: The acceptance face of women's smoking in Britain 1918-1970. Gender \& History, 15(2), 342-360.

Tinkler, P. (2006). Smoke signals: Women smoking and visual culture in Britain. Oxford: Berg.

Veday, T. F. (2014). Tracing the cigarette epidemic: An age-period-cohort study of education, gender and smoking using a pseudo-panel approach. Social Science Research, 48, 35-47.

Vlassoff, C., \& Garcia-Moreno, C. (2002). Placing gender at the center of health programming: Challenges and limitations. Social Science \& Medicine, 54(11), 1713-1723.

Woodward, A., \& Kawachi, I. (2000). Why reduce health inequalities? Journal of Epidemiology and Community Health, 54, 923-929.

Yurekli, A. A., \& Zhang, P. (2000). The impact of clean indoor-air laws and cigarette smuggling on demand for cigarettes: An empirical model. Health Economics, 9(1), 159-170.

Publisher's Note Springer Nature remains neutral with regard to jurisdictional claims in published maps and institutional affiliations. 